\title{
Comparative study of metal induced phospholipid modifications in the heavy metal tolerant filamentous fungus Paecilomyces marquandii and implications for the fungal membrane integrity*
}

\author{
Mirosława Słaba, Przemysław Bernat, Sylwia Różalska, Justyna Nykiel and Jerzy Długoński ${ }^{\circledR}$ \\ Department of Industrial Microbiology and Biotechnology, Faculty of Biology and Environmental Protection, University of Łódź, Łódź, Poland
}

In this work we compared the effect of five heavy metals: $\mathrm{Zn}, \mathrm{Pb}, \mathrm{Cd}, \mathrm{Ni}$ and $\mathrm{Cu}$ on phospholipid composition of the ubiquitous soil fungus Paecilomyces marquandii, originating from a strongly metal polluted area and characterized by high tolerance to these elements. $\mathrm{Cd}, \mathrm{Ni}$ and $\mathrm{Cu}$ caused an increase in phosphatidylcholine (PC). Only $\mathrm{Pb}$ decreased $\mathrm{PC}$ content, which was accompanied by a significant rise in the phosphatidic acids (PA) level, probably due to activation of phospholipase $D$ which hydrolyzes PC to PA. This could result in membrane fluidity disturbance, and thus affect its integrity. The assessment of propidium iodide influx showed strong disturbance of membrane integrity for $\mathrm{Cu}$ and $\mathrm{Pb}$ stressed mycelia, whereas mycelia treated with $\mathrm{Ni}$ were impermeable to this dye. The results obtained revealed a strong $\mathrm{Cu}$ and $\mathrm{Pb}$ toxicity involving disruption of membrane integrity. $\mathrm{Pb}$ action was reflected by lipid composition, whereas changes in $\mathrm{Cu}$ treated mycelia did not completely elucidate its harmful effect on the membrane, which was most probably caused by $\mathrm{Cu}$ induced lipid peroxidation. $\mathrm{Zn}$ did not induce quantitative changes in PC and phosphatidylethanolamine (PE) but caused changes in phospholipid lipid saturation, which appears to be important for fungus adaptation to the presence of metals. The enhanced PC content balanced by higher PC saturation can help in the maintenance of proper membrane fluidity and result in alleviating the $\mathrm{Cd}$ and $\mathrm{Ni}$ induced stress. These results will allow to clarify the mechanism of $\mathrm{Pb}$ toxicity and help to elucidate the cellular basis of fungal membrane adaptation to heavy metals.

Key words: heavy metals, membrane integrity, phospholipids, Paecilomyces marquandii

Received: 30 October, 2013; revised: 02 December, 2013; accepted: 03 December, 2013; available on-line: 30 December, 2013

\section{INTRODUCTION}

Phospholipids (PLs), constituting about $70 \%$ of all membrane lipids, are the major structural lipids in eukaryotic membranes and play a pivotal role in the membrane fluidity and permeability regulation (de Kroon et al., 2013). Phosphatidylcholine (PC) and phosphatidylethanolamine (PE) are the most abundant PLs in the eukaryotic cells including yeast and fungi and perform crucial functions in the maintenance of membrane integrity. Although fungal PLs are synthetized via pathways common to higher eukaryotic organisms, differences in their composition and functions have been found. For example, in contrast to plants, phosphatidylglicerol in fungi is produced in negligible amounts, mainly as a metabolic precursor of cardiolipine, a lipid important for cell growth, anaerobic metabolism and mitochondrial function (Šimočková et al., 2008). Phosphatidylserine (PS) is crucial in biology of higher eukaryotes contributing to PE and PC synthesis, whereas PS does not play such an essential role in yeast (Vance \& Streenbergen, 2005; de Kroon et al., 2013). Phosphatidic acid (PA), a lipid signal, is synthetized in a minor amount in normal growth conditions, but its pool can significantly rise under stress conditions (Quartacci et al., 2001). It was documented that PA plays a central role in the transcriptional regulation of phospholipid synthesis in Saccharomyces cerevisiae (Carman \& Henry, 2007). Phosphatidylinositol (PI) is a minor membrane component, but it serves as a precursor of sphingolipids, ceramides and glycosylphosphatidyl inositol anchors of proteins which are essential in eukaryotic microorganisms (Orlean \& Menon, 2007; Reynolds, 2009).

PLs are considered to be the most sensitive to alterations under environmental stress exposure (Dercová et al., 2004; de Kroon et al., 2013).

Heavy metal toxicity to living cells can be manifested by an increase in membrane permeability leading to disruption of the membrane function. However, the mechanism involved in heavy metal induced toxicity has not been fully understood. Azavedo et al. (2007) reported that $\mathrm{Cu}$ induced oxidative damage to the fungal cell membrane. Lipid peroxidation was also involved in the toxic action of $\mathrm{Cu}$ and $\mathrm{Cd}$ against the yeast membrane (Howlett \& Avery, 1997; Chmielowska-Bak et al., 2013). $\mathrm{Cd}, \mathrm{Cu}$ and $\mathrm{Hg}$ promoted enhanced membrane permeability and generated reactive oxygen species in mitochondria (Belyaeva et al., 2004).

Additionally, heavy metals can interrupt synthesis of lipids and fatty acids in microscopic fungi (Čertík et al., 2005; Paraszkiewicz et al., 2009; Słaba et al., 2013). An increase in the trans/cis ratio of unsaturated fatty acids in the presence of metals was observed. Trans isomers are more stable than cis and can counteract the membrane disturbance (Kaur et al., 2005). A reduction in polyunsaturated fatty acid production caused by some heavy metals was noted (Garcia et al., 2005; Paraszkiewicz et. al., 2010). On the other hand, microorganisms, espe-

e-mail: jdlugo@biol.uni.lodz.pl

*Presented at the 3-rd Workshop on Microbiology "MIKROBIOT 2013" in Łódź, Poland.

Abbreviations: DBI, double-bond index; PA, phosphatidic acid; PC, phosphatidylcholine; PE, phosphatidylethanolamine; PI, phosphatidylinositol; PLs, phospholipids; PS, phosphatidylserine 
cially fungi inhabiting polluted environments, can evolve many adaptive mechanisms to limit heavy metal toxicity and simultaneously contribute to their removal (e.g. extracellular polymer production, cell wall and membrane modification or metal sequestration) (Paraszkiewicz et al., 2007; Gadd, 2010; Słaba \& Długoński, 2011). Therefore, a better understanding of the mechanisms allowing fungi to survive at high metal concentrations has a great environmental and biotechnological importance.

In our earlier report, details of $\mathrm{Zn}$ and $\mathrm{Pb}$ toxicity to germinating spores of Paecilomyces marquandii were described (Słaba et al., 2005). It was also found that this filamentous fungus can effectively bind $\mathrm{Zn}$ and $\mathrm{Pb}$ (Słaba \& Długoński, 2011).

In this work we studied comparatively the effect of zinc, lead, cadmium, nickel and copper ions on phospholipids of P.marquandii strain and the metal treatment implications for fungal membrane integrity.

\section{MATERIALS AND METHODS}

Chemicals. Metal salts (acetates) were purchased from Sigma-Aldrich Chemical Co. (Germany). Propidium iodide used to demonstrate the condition of the membrane was purchased from Molecular Probes, Eugene (Oregon, USA). Five analytical standards of a given class of phospholipids ( $>99 \%$ purity): 1,2-dimyristoyl-sn-glycero-3-phospho-rac-(1-glycerol) (sodium salt) (14:0/14:0 PG); 1,2-dilauroyl-sn-glycero-3-phosphoethanolamine (12:0/12:0 PE), 1,2- dimyristoyl-sn-glycero-3-phosphocholine (14:0/14:0 PC); L-R-phosphatidylinositol (PI) sodium salt from bovine liver; 1,2-dimyristoyl-sn-glycero-3-phospho-L-serine sodium salt (14: 0/14:0 PS), and 1,2-dimyristoyl-sn-glycero-3-phosphate (sodium salt) (14:0/14:0 PA) were obtained from Avanti Polar Lipids, Inc.(Alabaster, USA). Other chemicals used in this study were from J.T. Baker, Sigma and POCh.

Microorganism cultures. A filamentous fungus Paecilomyces marquandii isolated from post-flotation tailings of Non-Ferrous Metal Works 'Szopienice' (Katowice, Poland), strongly polluted with heavy metals, was the subject of this work. This strain was stored at ZT slants (composition in $\mathrm{g}^{-1}$ : glucose, 4; Difco yeast extract, 4; agar, 25; malt extract $6-11^{\circ} \mathrm{Blg}\left(1^{\circ}\right.$ Balling $=1 \mathrm{~g}$ of soluble substances extracted from the grain per $100 \mathrm{ml}$ malt extract); $\mathrm{pH}$ 7.0) in the collection of the Department of Industrial Microbiology and Biotechnology, University of Lodz, Poland (IM 6003). 7-day spores were introduced into $20 \mathrm{ml}$ Sabouraud medium (composition described by Lisowska et al., 2006) in $100 \mathrm{ml}$ Erlenmeyer flasks. Preculture was prepared as presented previously (Słaba et al., 2013). After $24 \mathrm{~h}, 15 \%$ of inoculum was added to Sabouraud medium, supplemented with the following concentrations of $\mathrm{Zn}, \mathrm{Cu}, \mathrm{Pb}, \mathrm{Ni}$ and $\mathrm{Cd}$, inhibiting fungal growth by $50 \%: 12,4.5,3.7,3.0,2.5 \mathrm{mM}$, respectively. Control samples without the metal supplementation were prepared simultaneously. The cultures were grown for 5 days on a rotary shaker $\left(160\right.$ r.p.m.) at $28^{\circ} \mathrm{C}$. Next, mycelia samples were washed and separated for further analyses. To check the permeability of the fungal membrane, the samples $(1 \mathrm{ml})$ were collected after $24 \mathrm{~h}$ incubation, washed twice with deionized water and phosphate buffer and stained with propidium iodide.

Phospholipid extraction and sample preparation. Samples were prepared according to the method described by Folch et al. (1957) with modifications. Fresh wet mycelia $(1.0 \mathrm{~g})$ were homogenized in a mortar with $10 \mathrm{ml}$ of a mixture containing chloroform : methanol (2
$: 1, \mathrm{v} / \mathrm{v})$. After $18 \mathrm{~h}$ incubation at room temperature the samples were vortexed for $1 \mathrm{~min}$. Next, $5 \mathrm{ml}$ of a fresh extraction mixture was added and vials were vortexed again for $1 \mathrm{~min}$. After filtration through a paper filter, $0.02 \mathrm{ml}$ of lipid standards (one standard from each class: PA, PE, PC, PS, PI, PG at the concentration of $0.1 \mathrm{mg}$ $\mathrm{ml}^{-1}$ ) and $3.0 \mathrm{ml}$ of $0.8 \% \mathrm{NaCl}$ were introduced into the supernatants and the samples were again vortexed for $1 \mathrm{~min}$. The organic phases were collected, dried up with anhydrous sodium sulfate and evaporated under reduced pressure at $40^{\circ} \mathrm{C}$. Evaporated residues were dissolved in $2 \mathrm{ml}$ of methanol and $0.2 \mathrm{ml}$ was transferred onto chromatography plates for analysis.

HPLC-MS/MS analysis. The LC-MS analysis of phospholipids was carried out on an Agilent 1200 HPLC system (Santa Clara CA, USA) coupled to a 3200 Q-Trap mass spectrometer (Ab Sciex, Framingham, MA, USA). The total phospholipid sample was separated on an Al-

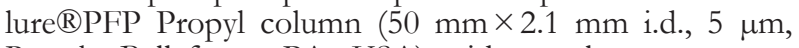
Restek, Bellafonte, PA, USA) with a column temperature of $40^{\circ} \mathrm{C}$. Mobile phase A consisted of water $/ 5 \mathrm{mM}$ ammonium formate, and mobile phase $B$ consisted of methanol/5 $\mathrm{mM}$ ammonium formate. A linear gradient program was set as follows: $0-2 \mathrm{~min}, 80-100 \% \mathrm{~B}$; 2-4 $\min , 100 \% \mathrm{~B}$; 4-6 $\mathrm{min}, 100-80 \% \mathrm{~B}$. Injection volume

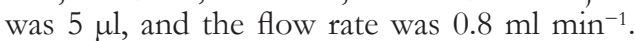

The nitrogen drying gas and turbo gas were at 50 and 60 psi, respectively. The curtain gas that prevents contamination of the ion was set at 25 psi. Different phospholipid classes were identified using a Precursor ion scan $(m / z, 153)$ as a survey scan (range $m / z$ 650-950, scan speed $1000 \mathrm{Da} \mathrm{s}^{-1}$, collision energy $40 \mathrm{eV}$ ); an enhanced resolution (ER) scan was used to confirm phospholipid mass assignments. An EPI scan was used as a dependent scan (range m/z 100-950, scan speed 1000 $\mathrm{Da} \mathrm{s}^{-1}$, collision energy $40 \mathrm{eV}$ ). Based on the product ion and precursor ion analysis of the obtained phospholipid species, a list of multiple reaction monitoring (MRM) transitions was constructed. The MRM mode was used for relative quantitation of individual phospholipids.

Membrane integrity assay. For the membrane integrity assay, hyphaes suspended in phosphate buffered saline $(0.1 \mathrm{M}, \mathrm{pH}=7.4)$ were stained with propidium iodide at the final concentration of $1 \mathrm{mg} \mathrm{ml}^{-1}$, for $5 \mathrm{~min}$, at room temperature in the dark. The residual dye was removed by centrifugation (15000 r.p.m.) and samples were washed three times in the same buffer as described above. The images of stained hyphaes were captured using a Confocal Laser Scaning Microscope (Pascal 2, Zeiss) combined with an Axiovert 200M (Zeiss, Germany) inverted microscope equipped with a Plan-Apochromat objective $(63 \times / 1.25$ Oil). All settings were held constant during the course of all experiments. The PI fluorescence was detected with a He-Ne laser (543 nm) and an LP filter set (560-615 nm) and images of the hyphaes were collected at Nomarski DIC at the excitation of 488 $\mathrm{nm}$ of an Ar laser.

The percentages of membrane damaged hyphaes were calculated as follows: (total area of PI stained hyphaes/ total area of hyphaes) $\times 100$. The values were calculated from at least 10 microphotographs from 3 independent experiments.

Statistical analysis. All experiments were done in triplicate. One-way analysis of variance (ANOVA) was performed to determine the significance of differences between the samples using Excel 2007 (Microsoft Corporation, USA). 
Table 1. Relative content (mol\%) of major phospholipid classes extracted from heavy metal stressed $P$. marquandii mycelia.

\begin{tabular}{|c|c|c|c|c|c|c|}
\hline Class of phospholipids & control & $\mathrm{Zn}$ & $\mathrm{Pb}$ & $\mathrm{Cd}$ & $\mathrm{Ni}$ & $\mathrm{Cu}$ \\
\hline PA & $3.83 \pm 0.36$ & $5.60 \pm 1.87$ & $16.12^{* *} \pm 5.28$ & $4.25 \pm 2.36$ & $3.71 \pm 1.53$ & $2.59 \pm 1.21$ \\
\hline $\mathrm{PE}$ & $47.49 \pm 2.57$ & $54.80^{* *} \pm 2.69$ & $48.57 \pm 3.10$ & $33.18^{* *} \pm 3.59$ & $43.64 \pm 6.00$ & $38.58^{* *} \pm 3.32$ \\
\hline PS & $10.16 \pm 1.08$ & $2.23^{* *} \pm 0.59$ & $10.18 \pm 6.03$ & $2.18^{* *} \pm 1.30$ & $1.36^{* *} \pm 0.65$ & $1.13^{* *} \pm 0.34$ \\
\hline PC & $34.31 \pm 3.55$ & $36.76 \pm 2.79$ & $22.62^{* *} \pm 6.64$ & $59.40^{* *} \pm 4.19$ & $50.42^{* *} \pm 5.06$ & $56.75^{* *} \pm 3.49$ \\
\hline $\mathrm{PI}$ & $4.21 \pm 2.11$ & $0.71^{* *} \pm 0.05$ & $2.51 \pm 0.97$ & $1.00^{*} \pm 0.58$ & $0.85^{* *} \pm 0.56$ & $0.95^{* *} \pm 0.25$ \\
\hline $\mathrm{PC} / \mathrm{PE}$ ratio & $0.73 \pm 0.11$ & $0.70 \pm 0.08$ & $0.48^{* *} \pm 0.16$ & $1.82^{* *} \pm 0.32$ & $1.18^{* *} \pm 0.27$ & $1.46^{* *} \pm 0.16$ \\
\hline
\end{tabular}

PA, phosphatidic acid; PC, phosphatidylcholine; PE, phosphatidylethanolamine; PI, phosphatidylinositol; PS, phosphatidylserine. Data are mean values \pm S.D.* ${ }^{* *}$ Indicate values that differ significantly from the control at $P<0.05$ and $<0.01$ respectively. Metal concentrations (mM) inhibiting fungal growth by ca. 50\% were used as follows: Cd 2.5, Ni 3.0, Pb 3.7, Cu 4.5, Zn 12.

A double-bond index (DBI), which indicates the saturation level of lipids, was calculated according to the equation described by Su et al. (2009).

\section{RESULTS}

\section{Phospholipids composition in P. marquandii cultures supplied with heavy metals}

Lipidomic analysis of organic extracts of $P$. marquandii cultures not supplemented with heavy metals revealed the presence of 30 phospholipids from five classes (Table 1, Fig. 1). Phosphatidylcholines were the most numerously (9) represented: 16:0/18:2, 16:0/18:1, 16:0/18:0, 18:2/18:2, 18:1/18:2, 18:0/18:2, 18:1/18:1, 18:0/18:1, 18:0/18:1, followed by phosphatidylethanolamines (6): 16:0/18:2, 16:0/18:1, 18:1/18:0, 18:2/18:2, 18:1/18:2, 18:1/18:1, phosphatidic acids (6): 16:0/18:2, 16:0/18:1, 18:2/18:2, 18:2/18:1, 18:1/18:1, 18:1/18:0, phosphatidylserines (6): 16:0/18:2, 16:0/18:1, 18:1/18:2, 18:1/18:1, 18;/18:1, 18:0/18:0 and (not shown in Fig. 1) phosphatidylinositols (3): 16:0/18:2, 16:0/18:1, 18:0/18:1. Fungal phospholipids contained 4 fatty acids (16:0, 18:0, $18: 1,18: 2)$. The same fatty acids dominated in total fatty acids isolated from cultures of the $P$. marquandii treated with heavy metals (Słaba et al., 2013).

The percentage composition of the main class of PLs is shown in Table 1. PE and PC were the most abundant phospholipids in P. marquandii and constituted around 55 and $32 \%$ of total phospholipids present in the control samples. 5-day heavy metal exposure at the concentrations which inhibited growth by about $50 \%$ induced different changes in the phospholipid composition.

Only $\mathrm{Zn}$ did not affect the PC and PE content. An elevated PC level was observed after $\mathrm{Cd}, \mathrm{Ni}$ and $\mathrm{Cu}$ treatment. In the case of $\mathrm{Cd}$ and $\mathrm{Cu}$ a rise in $\mathrm{PC}$ was correlated with a significant drop in PE. In contrast, only $\mathrm{Pb}$ induced a decrease in the PC level and the PC/ $\mathrm{PE}$ ratio. All the metals caused a decrease in the PI level and almost all (with the exception of $\mathrm{Pb}$ ) reduced the PS abundance. Additionally, an increase in PA was noticed for $\mathrm{Pb}$ supplemented cultures (from 3.83 to $16.12 \%$ ). The above mentioned PL alteration and its implications will be discussed in the Discussion Section.

\section{Changes in phospholipid fatty acids and saturation}

Quantitative differences among major fatty acids, which are part of phospholipids isolated after metal exposure are illustrated in Fig. 1. Although no qualitative changes were observed, significant quantitative variations were related to the fatty acid abundance in PC and PE and caused an increase or decrease in the DBI value, depending on a particular metal (Table 2).

Zinc induced a statistically significant rise in fatty acid unsaturation in PE, PC and PI. DBI variations in zinc supplemented cultures were mainly caused by an increased content of PE 16:0/18:2, PE 18:2/18:2 and PC 18:2/18:2 (Fig. 1). The amounts of more unsaturated species significantly decreased in the fungal cultures cultivated in the presence of $\mathrm{Pb}, \mathrm{Cd}$ and $\mathrm{Ni}$, which resulted in a DBI decline in the PC class (also in PE and PS in $\mathrm{Cd}$ treated mycelia). Interestingly, the marked changes in the composition of particular PL classes did not correlate with changes in their saturation in $\mathrm{Cu}$ stressed samples (Table1 and Table 2).

\section{Membrane integrity of metal stressed mycelia}

The condition of a fungal membrane exposed to heavy metals was estimated by the measurement of propidium iodide intracellular accumulation (Table 3). This dye is impermeable to intact cells, whereas its influx into hyphaes demonstrates disruption of membrane integrity. $\mathrm{Cu}$ and $\mathrm{Pb}$ caused a strong disruption of P.marquandii membrane integrity. Propidium iodide was present in

Table 2. A double-bond index of phospholipids isolated from P. marquandii cultures exposed to heavy metal ions at the concentration inhibiting growth by about $50 \%$.

\begin{tabular}{lllllll}
\hline Class of phospholipids & control & $\mathrm{Zn}$ & $\mathrm{Pb}$ & $\mathrm{Cd}$ & $\mathrm{Ni}$ & $\mathrm{Cu}$ \\
\hline PA & $2.24 \pm 0.14$ & $2.32 \pm 0.09$ & $2.22 \pm 0.15$ & $2,20 \pm 0.14$ & $2.12 \pm 0.06$ & $3.05 \pm 1.65$ \\
\hline PE & $2.31 \pm 0.04$ & $2.50^{* *} \pm 0.02$ & $2.39 \pm 0.17$ & $2.14^{* *} \pm 0.07$ & $2.27 \pm 0.08$ & $2.32 \pm 0.04$ \\
\hline PS & $1.81 \pm 0.43$ & $1.67 \pm 0.05$ & $1.76 \pm 0.10$ & $1.42 \pm 0.09$ & $1.47 \pm 0.16$ & $1.59 \pm 0.09$ \\
\hline PC & $2.97 \pm 0.03$ & $3.11^{* *} \pm 0.05$ & $2.80^{* *} \pm 0.07$ & $2.57^{* *} \pm 0.03$ & $2.88^{* *} \pm 0.04$ & $3.00 \pm 0.12$ \\
\hline PI & $1.55 \pm 0.06$ & $1.71^{* *} \pm 0.02$ & $1.31 \pm 0.20$ & $1.57 \pm 0.13$ & $1.58 \pm 0.05$ & $1.76^{*} \pm 0.13$ \\
\hline
\end{tabular}

PA, phosphatidic acid; PC, phosphatidylcholine; PE, phosphatidylethanolamine; PI, phosphatidylinositol; PS, phosphatidylserine. Data are mean values \pm S.D. ${ }^{*}, * *$ Indicate values that differ significantly from the control at $P<0.05$ and $<0.01$ respectively. 


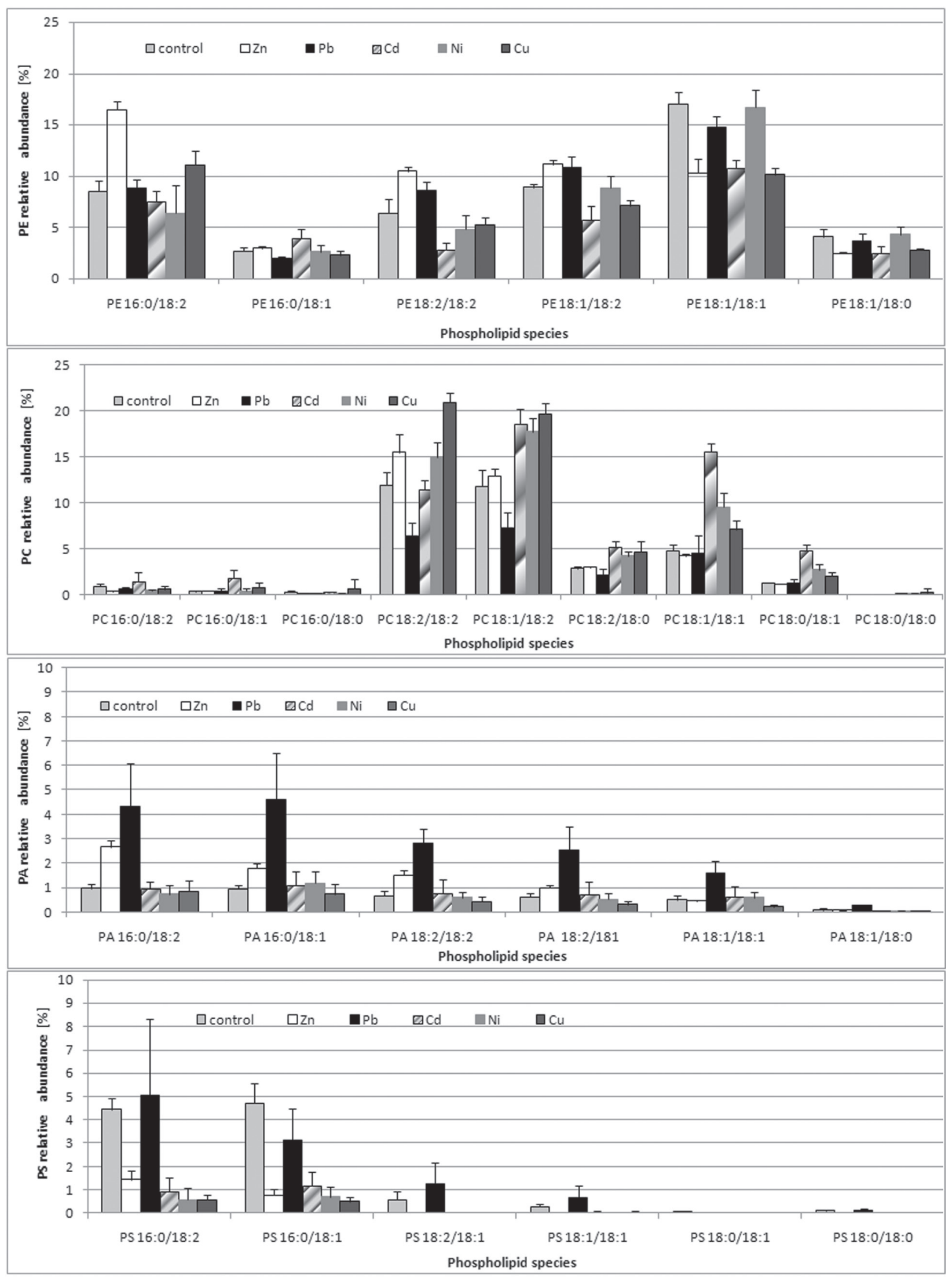

Figure 1. Fatty acid composition in a particular class of phospholipids (PE, PC, PA and PS) isolated from P. marquandii cultured in the presence of $\mathrm{Zn}, \mathrm{Pb}, \mathrm{Cd}$, $\mathrm{Ni}$ and $\mathrm{Cu}$ ions. 
Table 3. P. marquandii hyphaes permeability determined with propidium iodide after heavy metal treatment.

$\begin{array}{ll}\text { Samples } & \text { Permeability to propidium iodide (\%) } \\ \text { Control } & 1.10 \pm 0.85 \\ \mathrm{Zn} & 3.01 \pm 1.22 \\ \mathrm{~Pb} & 31.69 \pm 4.75 \\ \mathrm{Cd} & 3.47 \pm 0.34 \\ \mathrm{Ni} & 0.00 \pm 0.00 \\ \mathrm{Cu} & 41.62 \pm 6.78\end{array}$

Data are mean values \pm S.D. All samples differ significantly from the control at $P \leq 0.02$

41.6 and $31.7 \%$ of hyphaes surface for $\mathrm{Cu}$ and $\mathrm{Pb}$ treated samples, in comparison to $1.10 \%$ in the case of control hyphaes. $\mathrm{Cd}$ and $\mathrm{Zn}$ treated mycelia maintained an intact membrane (permeability reached 3.47 and 3.01\% for this dye, respectively). Interestingly, after $\mathrm{Ni}$ exposure the mycelia were totally impermeable to propidium iodide $(0.0 \%)$

\section{DISCUSSION}

The phospholipid composition, lipid acyl chain length and saturation determine the physical properties of the membrane (de Kroon, 2007; de Kroon et al., 2013). Because PC and PE play a crucial role in the maintenance of proper fluidity and permeability of the membrane, their variability seems to be particularly important (Quartacci et al., 2001; Bou Khalil et al., 2010). Niebergal \& Vance (2012) found that the total cellular amount of $\mathrm{PC}$ and PE influences growth and membrane integrity of animal cells. It was documented that PC tends to form a bilayer, whereas PE has a strong propensity to build a nonbilayer hexagonal phase (Quartacci et al., 2001; Bou Khalil et al., 2010). Welti et al. (2002) explained that the transformation of a membrane lipid bilayer into a nonbilayer structure deteriorates membrane integrity and cell functions. The results obtained here, revealed a reduced level of PC and an increased level of PA in Pb supplemented mycelia, combined with enhanced propidium iodide influx, indicating a strong membrane permeabilisation. In our earlier work we documented peroxidation of $P$. marquandii lipids as a result of the toxic action of $\mathrm{Pb}, \mathrm{Ni}$ and $\mathrm{Cu}$. Although all tested metals induced a statistically important increase in the electrolyte leakage, the efflux level was two-fold higher in $\mathrm{Pb}$ treated mycelia than in mycelia treated with other metals (Słaba et al., 2013). This work extends the knowledge of $\mathrm{Pb}$ toxicity towards membrane lipids of $P$. marquandii. We conclud that a drop in PC and a rise in PA destabilises the balance between the bilayer and nonbilayer structure and promotes nonbilayer phase formation, leading to decreased viability through membrane integrity perturbation. A similar mechanism for a freezing stress was documented in Arabidopsis plants (Welti et al., 2002). The authors had shown that changes in the PC and PA levels were caused by phospholipase D, which hydrolysed PC to $\mathrm{PA}$. Additionally, our study concerning $\mathrm{Pb}$ toxicity to phospholipids is in line with the supposition of $\mathrm{Li}$ et al. (2006) suggesting that a PC/PE ratio can regulate membrane integrity and a drastic drop in PC/PE may lead to cell death.

An elevated level of PC enhancing membrane fluidity (Quaracci et al., 2001; Bernat et al., in press) was observed in mycelia exposed to $\mathrm{Cd}, \mathrm{Ni}$ and $\mathrm{Cu}$, but the effect of these metals on membrane integrity varied. $\mathrm{Cd}$ and $\mathrm{Ni}$ most strongly inhibited growth of the tested fun- gus (Słaba et al., 2013), but a measurement of propidium iodide influx, impermeable to intact cells, showed that membrane integrity was not disturbed. As observed for $\mathrm{Cd}$ and especially for $\mathrm{Ni}$, enhanced PC content, together with its higher saturation than in the control samples, can counteract PC fluidizing effect and allow to maintain proper fluidity of the membrane. In contrast, $\mathrm{Cu}$ treatment, apart from causing a rise in PC level and PC/PE ratio, simultanously led to greater damage to the $P$. marquandii membrane. Similar results were obtained by Azavedo et al. (2007), who found that $\mathrm{Cu}$ induced a strong disruption of membrane integrity in aquatic hyphomycetes fungi. The mechanism of $\mathrm{Cu}$ toxicity to microorganisms by inducing membrane perturbation is well documented (Stohs \& Bagchi, 1995; Azavedo et al., 2007). It depends on the fatty acid membrane composition (Avery et al., 1996). On the other hand, $\mathrm{Cu}$, as a transition metal, contributes to oxidative membrane damage (Azavedo et al., 2007). These observations are in accord with our earlier results showing enhanced lipid peroxidation in mycelia under $\mathrm{Cu}$ exposure (Słaba et al., 2013).

In the case of $\mathrm{Zn}$, changes in the lipid fatty acid saturation appear to be important for metal adaptation. A significant rise in phospholipid unsaturation was detected for PE, PC and PI mainly due to linoleic acid enrichment. Probably, enhanced production of unsaturated fatty acids balanced the elevated level of PE, which was more saturated than PC in all fungal samples. A high level of PE enhanced membrane rigidity (Quaracci et al., 2001, Bernat et al., in press). A rigidification of membrane lipids in the rat liver was involved in the membrane damage by cisplastin (Martins et al., 2008).

There is a discrepancy in the attitude towards the role of linoleic acid in microorganism adaptation. Howlett \& Avery (1997) documented that Saccharomyces cerevisiae sensitivity to cadmium ions increased with the higher degree of fatty acids unsaturation and was supported by metal induced membrane permeability, leading to the reduction in yeast viability. In contrast, Masia et al. (1998) reported that linoleic acid supplementation partially neutralizes the toxicity of tributyltin to $S$. cerevisae. Alteration in the cellular level of a single polyunsaturated fatty acid, especially in the linoleic acid content, may also lead to changes in metal sensitivity (Avery et al., 1996).

In summary, we suggest that linoleic acid abundance diminishes the membrane perturbation. $\mathrm{Cu}$ and $\mathrm{Pb}$ strongly affect the membrane integrity. The toxicity of $\mathrm{Cu}$ against the membrane occurs probably as a consequence of lipid peroxidation, whereas $\mathrm{Pb}$ toxicity is caused by both oxidative membrane damage and deterioration of the membrane integrity due to a drop in PC level.

\section{Acknowledgements}

This study was supported by the National Science Centre in Cracow, Poland (Project No. UMO2011/01/B/NZ9/02898).

\section{REFERENCES}

Avery SV, Howlett NG, Radice S (1996) Copper toxicity towards Saccharomyces cerevisiae: dependence on plasma membrane fatty acid composition. Appl Environ Microb 62: 3960-3966.

Azevedo MM, Carvalho A, Pascoal C, Rodrigues F, Fernanda C (2007) Responses of antioxidant defenses to $\mathrm{Cu}$ and $\mathrm{Zn}$ stress in two aquatic fungi. Sci Total Environ 377: 233-243.

Belyaeva EA, Glazunov VV, Korotkov SM (2004) $\mathrm{Cd}^{2+}$-promoted mitochondrial permeability transition: a comparison with other heavy metals. Acta Biochim Pol 51: 545-551. 
Bernat P, Gajewska E, Bernat T, Wielanek M Characterisation of the wheat phospholipid fraction in the presence of nickiel and/or selenium. Plant Growth Regul DOI 10.1007/s10725-013-9848-x.

Bou Khalil M, Hou W, Zhou H, Elisma F, Swayne LA, Blanchard AP, Yao Z, Bennett SAL, Figeys D (2010) Lipidomics era: accomplishments and challenges. Mass Spectrom Rev 29: 877-929.

Carman GM, Henry SA (2007) Phosphatidic acid plays a central role in the transcriptional regulation of glycerophospholipid synthesis in Saccharomyces cerevisiae. J Biol Chem 282: 37293-37297.

Čertík M, Breierová E, Juršíková P (2005) Effect of cadmium on lipid composition of Aureobasidium pullulans grown with added extracellular polysaccharides. Int Biodeter Biodegr 55: 195-202.

Chmielowska-Bakk J, Izbiańska K, Deckert J (2013) The toxic Doppelganger: on the ionic and molecular mimicry of cadmium. Acta Biochim Pol 60: 369-374.

de Kroon AIPM (2007) Metabolism of phosphatidylcholine and its implications for lipid acyl chain composition in Saccharomyces cerevisiae. Biochim Biophys Acta 177:1 343-352.

de Kroon AIPM, Rijken PJ, De Smet CH (2013) Checks and balances in phospholipid class and acyl chain homeostasis, the yeast perspective. Prog Lipid Res 52: 374-394.

Dercová K, Čertík M, Mal'ová A, Sejáková Z (2004) Effect of chlorophenols on the membrane lipids of bacterial cells. Int Biodeter Biodegr 54: 251-254.

Folch J, Lees M, Sloane-Stanley G (1957) A simple method for the isolation and purification of total lipides from animal tissues. $J$ Biol Chem 199: 833-841.

Gadd GM (2010) Metals, minerals and microbes: geomicrobiology and bioremediation. Microbiology 156: 609-643.

Garcia JJ, Martinez-Ballarin E, Millan-Plano S, Allue JL, Albendea C, Fuentes L, Escanero JF (2005) Effects of trace elements on membrane fluidity. I Trace Elem Med Biol 19: 19-22.

Howlett NG, Avery SV (1997) Relationship between cadmium sensitivity and degree of plasma membrane fatty acid unsaturation in Saccharomyces cerevisiae. Appl Microbiol Biot 48: 539-545.

Kaur A, Chaudhary A, Kaur A, Choudhary R, Kaushik R (2005) Phospholipid fatty acid - a bioindicator of environment monitoring and assessment in soil ecosystem. Curr Sci 89: 1103-1112.

Li Z, Agellon LB, Allen TM, Umeda M, Jewell L, Mason A, Vance DE (2006) The ratio of phosphatidylcholine to phosphatidylethanolamine influences membrane integrity and steatohepatitis. Cell Metab 3: $321-331$.

Lisowska K, Szemraj J, Różalska S, Długoński J (2006) The expression of cytochrome P-450 and cytochrome P-450 reductase genes in the simultaneous transformation of corticosteroids and phenanthrene by Cunninghamella elegans. FEMS Micrbiol Lett 261: 175-180.

Martins MN, Santos NA, Curti C, Bianchi ML, Santos AC (2008) Cisplatin induces mitochondrial oxidative stress with resultant energetic metabolism impairment, membrane rigidification and apoptosis in rat liver. J Appl Toxicol 28: 337-344.

Masia A, Avery SV, Zoroddu MA, Gadd GM (1998) Enrichment with a polyunsaturated fatty acid enhances the survival of Saccharomyces cerevisiae in the presence of tributyltin. FEMS Microbiol Lett 167: $321-326$.
Niebergal LJ, Vance DE (2012) The ratio of phosphatidylcholine to phosphatidylethanolamine does not predict integrity of growing MT58 Chinese hamster ovary cells. Biochim Biophys Acta 1821: 324 334.

Orlean P, Menon AK (2007) Thematic review series: lipid posttranslational modifications. GPI anchors of protein in yeast and mammalian cells, or: how we learned to stop worrying and low glycophospholipids. J Lipid Res 48: 993-1011.

Paraszkiewicz K, Bernat P, Długoński J (2009) Effect of nickel, copper, and zinc on emulsifier production and saturation of cellular fatty acids in filamentous fungus Curvularia lunata. Int Biodeter Biodegr 63: $100-105$.

Paraszkiewicz K, Bernat P, Naliwajski M, Długoński J (2010) Lipid peroxidation in the fungus Curvularia lunata exposed to nickel. Arch Microbiol 192: 135-141.

Paraszkiewicz K, Frycie A, Słaba M, Długoński J (2007) Enhancement of emulsifier production by Curvularia lunata in cadmium, zinc and lead presence. Biometals 20: 797-805.

Quartacci MF, Cosi E, Navari-Izzo F (2001) Lipids and NADPH-dependent superoxide production in plasma membrane vesicles from roots of wheat grown under copper deficiency or excess. J Exp Bot 52: $77-84$.

Reynolds TB (2009) Strategies for acquiring the phospholipid metabolite inositol in pathogenic bacteria, fungi and protozoa: making and taking it. Microbiology 155: 1386-1396.

Šimočková M, Holič R, Tahotná D, Patton-Vogt J, Griač P (2008) Yeast Pgc1p (YPL206c) controls the amount of phosphatidylglycerol via a phospholipase C-type degradation mechanism. I Biol Chem 283: 17107-17115.

Słaba M, Bizukojć M, Pałecz B, Długoński J (2005) Kinetic study of toxicity of zinc and lead ions to the heavy metals accumulating fungus Paecilomyces marquandii. Bioproc Biosyst Eng 28: 185-197.

Słaba M, Długoński J (2011) Efficient $\mathrm{Zn}^{2+}$ and $\mathrm{Pb}^{2+}$ uptake by filamentous fungus Paecilomyces marquandii with engagement of metal hydrocarbonates precipitation. Int Biodeter Biodegr 65: 954-960.

Słaba M, Gajewska E, Bernat P, Fornalska M, Długoński J (2013) Adaptive alterations in the fatty acids composition under induced oxidative stress in heavy metal-tolerant filamentous fungus Paecilomyces marquandii cultured in ascorbic acid presence. Environ Sci Pollut R 20: 3423-3434.

Stohs SJ, Bagchi D (1995) Oxidative mechanisms in the toxicity of metal ions. Free Radical Bio Med 18: 321-336.

Su K, Bremer DJ, Jeannotte R, Welti R, Yang C (2009) Membrane lipid composition and heat tolerance in cool-season turfgrasses, including a hybrid bluegrass. I Am Soc Hort Sci 134: 511-520.

Vance JE, Steenbergen R (2005) Metabolism and functions of phosphatidylserine. Prog Lipid Res 44: 207-234.

Welti R, Li W, Li M, Sang Y, Biesiada H, Zhou HE, Rajashekar CB, Williams TD, Wang X (2002) Profiling membrane lipids in plant stress responses. Role of phospholipase D alpha in freezing-induced lipid changes in Arabidopsis. J Biol Chem 277: 31994-32002. 